\title{
MONITORAMENTO DA COLONIZAÇÃO PELO STAPHYLOCOCCUS AUREUS EM ALUNOS DE UM CURSO DE AUXILIAR DE ENFERMAGEM DURANTE A FORMAÇÃO PROFISSIONAL*
}

SANTOS, B.M.de O. Monitoramento da colonização pelo Staphylococcus aureus em alunos de um curso de auxiliar de enfermagem durante a formação profissional. Rev.latino-am.enfermagem, Ribeirão Preto, v. 8, n. 1, p. 67-73, janeiro 2000.

Tendo em vista o nosso objetivo de conhecer o quadro de colonização pelo Staphylococcus aureus em alunos de um curso de Auxiliar de Enfermagem, durante a formação profissional, realizamos a coleta de material da cavidade nasal $(\mathrm{N}) e$ mãos direita (Md) e esquerda (Me) de 42 alunos, em diferentes momentos da formação, relacionando as taxas com as atividades desenvolvidas durante a programação do curso. Os resultados evidenciaram uma oscilação nas taxas de colonização nos diferentes momentos e a possibilidade de transmissão recíproca do agente entre os alunos e os receptores dos cuidados prestados, considerando o tipo de contato mantido entre eles.

UNITERMOS: portador são, Staphylococcus aureus, estudo longitudinal

\section{INTRODUÇÃO}

A colonização do ser humano pelos microrganismos que irão fazer parte da sua microbiota normal tem início no nascimento. Ela não é uniforme no que se relaciona à qualidade e quantidade e se distribui pelas diferentes partes do corpo que estão em contato com o meio externo, principalmente pele e mucosas, ${ }^{5,9}$, podendo, em circunstâncias particulares, produzir a doença $^{18,21}$.

Ao albergar o agente potencialmente infectante, o organismo pode comportar-se de duas maneiras fundamentais: revelando-se como caso declarado ou clínico, com sinais e sintomas da moléstia clinicamente diagnosticáveis, ou então como, assintomático, genericamente conhecido como portador são, quando no momento do exame encontra-se destituído de sintomatologia, apesar de estar colonizado.

O Staphylococcus aureus, um dos agentes patogênicos dessa microbiota, tem sido indicado como o agente mais comum de infecções piogênicas localizadas na pele ou em regiões mais profundas como furúnculos, foliculites, osteomielites, endocardites, pneumonias e septicemias fatais ${ }^{4,8,18,19}$ e outros tipos de manifestações ${ }^{2,4,22}$. Seu principal reservatório é o homem, sendo que os percentuais de colonização variam de 60 a
$70 \%$, podendo atingir $100 \%$ nas crianças no quarto dia de vida, $20 \%$ em crianças de 6 meses a 2 anos de idade, 30 a $50 \%$ aos 5-6 anos, semelhantes aos dos adultos e $30 \%$ acima dos $60 \operatorname{anos}^{20,23}$. Em portadores que trabalham em ambiente hospitalar essas porcentagens podem variar de 30 a $70 \%$, podendo atingir até $90 \%$, dependendo das condições ambientais, dos próprios pacientes, do uso de antibióticos e da própria estrutura do hospital.

O microrganismo pode ser encontrado em várias partes do corpo como fossas nasais, garganta, intestinos e pele, sendo que cavidade nasal tem sido apontada como a área mais freqüentemente positiva e a mais importante fonte do mesmo ${ }^{13,23}$. As taxas de portadores nasais situamse na faixa de 20 a $50 \%$ para indivíduos normais, podendo ser influenciadas pela técnica de colheita e análise bacteriológica das amostras e pela duração do período de observação.

As mãos também têm sido consideradas uma importante fonte de amostras de Staphylococcus aureus e têm sido um dos principais meios de transmissão da bactéria, no ambiente hospitalar, de um paciente infectado para outro suscetível, de um paciente infectado para o executor dos cuidados e do executor dos cuidados para um paciente suscetível, contribuindo sensivelmente para o aumento das fontes e reservatórios de amostras resistentes ${ }^{1,6}$.

\footnotetext{
* Trabalho subvencionado pelo CNPq

** Professor Associado Aposentado do Departamento de Enfermagem Geral e Especializada da Escola de Enfermagem de Ribeirão Preto da Universidade de São Paulo
} 
Estudos sobre o papel epidemiológico das mãos na transmissão de infecções entre profissionais que exercem atividades em nível hospitalar, têm reconhecido a importância potencial das mesmas como fonte de eventuais infecções hospitalares ${ }^{14,15,16}$, bem como a possível relação entre as amostras isoladas de diferentes áreas anatômicas de um mesmo indivíduo, principalmente entre as da cavidade nasal e mãos, sugerindo que a maior parte dos estafilococos das mãos é de origem nasal ${ }^{13,17}$.

A trasmissão do Staphylococcus aureus pode se dar pelo contato direto que pressupõe uma superposição, ou pelo indireto, através de aerossóis, secreções, poeira, fômites e alimentos, cuja transferência envolve um intermediário no qual o microrganismo permanece até ser transferido ao hospedeiro. A transmissão de pessoa a pessoa é uma forma de contato direto e as portas de entrada para o acesso do agente infeccioso no novo hospedeiro são os orifícios naturais, as mucosas, a pele ou solução de continuidade existente nesta.

Considerando ser o trabalho dos profissionais de enfermagem, em instituições hospitalares, visivelmente marcado pelas características do trabalho manual junto ao paciente, o qual pressupõe uma proximidade física e um contato mais ou menos constante entre o executor e o receptor do cuidado, um tempo de permanência variável para a sua execução e, não raras vezes, um esforço físico por parte dos executores do mesmo é que nos propusemos a realizar este estudo na tentativa de conhecer o quadro de colonização pelo Staphylococcus aureus entre alunos de um curso de Auxiliar de Enfermagem, em diferentes momentos de sua formação profissional, relacionando as taxas encontradas com as atividades desenvolvidas durante o cumprimento da programação curricular do curso e com a possibilidade de transmissão recíproca do agente entre os alunos e os receptores da assistência prestada.

\section{METODOLOGIA}

Participaram do estudo 42 alunos matriculados no Curso de Auxiliar de Enfermagem do Centro Interescolar do Hospital das Clínicas da Faculdade de Medicina de Ribeirão Preto-USP (HCFMRP-USP) que possui duração de um ano, com carga horária de 1200 horas, das quais 450 são destinadas à teoria e 750 às atividades práticas. $\mathrm{O}$ conteúdo teórico sempre precede as atividades práticas e a grade curricular é agrupada em Áreas de Estudo que compreendem as disciplinas de Introdução à Enfermagem, Enfermagem Médica, Enfermagem Cirúrgica, Enfermagem Materno-Infantil, Ética Profissional e Enfermagem em Saúde Pública.

Os alunos foram submetidos à colheita de material da cavidade nasal (N) e mãos direita (Md) e esquerda (Me) em seis diferentes momentos da formação profissional, relacionados às mudanças de disciplinas da grade curricular, quando encontravam-se em bloco teórico do conjunto de conteúdos subseqüente ao último estágio curricular. Ela foi realizada em sala de aula, logo no início das atividades diárias, sem que os alunos tivessem oportunidade de lavar as mãos antes da mesma. No momento das colheitas não poderiam apresentar nenhuma lesão nas mãos e vias aéreas superiores ou qualquer sinal e sintoma de infecção, assim como não poderiam estar em esquema de antibioticoterapia.

Para a colheita do material foram utilizadas zaragatoas estéreis embebidas em solução salina seguindo técnica e seqüência descritas abaixo:

- cavidade nasal - através de atrito, com movimentos circulares em ambos os vestíbulos nasais, por três vezes; - mão direita e mão esquerda - friccionando, com movimentos firmes a face interdigital dos dedos polegar e indicador de cada mão, por seis vezes.

As zaragatoas foram encaminhadas ao Laboratório de Bacteriologia da Faculdade de Medicina de Ribeirão Preto - USP, no máximo duas horas após a primeira colheita, sendo semeadas em placas de ÁgarSangue para isolamento do Staphylococcus aureus. As colônias suspeitas foram submetidas à prova da coagulase em tubo com sangue de coelho normal + EDTA a $0,1 \%$, segundo técnica de BAYLISS \& $\mathrm{HAL}^{3}$.

No momento da primeira colheita foi preenchido um formulário contendo os dados de identificação dos alunos, indicação do uso habitual das mãos (dextro ou sinistro) e envolvimento com instituições de saúde, antes e/ou durante a sua formação. Neste mesmo formulário foi destinado um espaço para anotação dos resultados obtidos da bacteriologia das amostras de Staphylococcus aureus isoladas (Anexo 1).

As colheitas foram realizadas segundo o cronograma abaixo:

- PRIMEIRA COLHEITA - (em 21/02/) no início do curso, antes dos alunos serem introduzidos em atividades práticas a nivel hospitalar;

- SEGUNDA COLHEITA - (em 03/05) após o bloco teórico e estágio supervisionado de Introdução à Enfermagem em unidades de internação médicocirúrgicas, primeiro contato com o ambiente hospitalar; - TERCEIRA COLHEITA - (em 04/07) após a conclusão da disciplina de Enfermagem Médica em enfermarias de Clínica Médica, Unidade de Moléstias Infectocontagiosas, Neurologia e Dermatologia;

- QUARTA COLHEITA - (em 12/09) após a conclusão da disciplina de Enfermagem Cirúrgica em enfermarias de Clínica Cirúrgica, Ortopedia e no Centro Cirúrgico; - QUINTA COLHEITA - (em 07/11) nesta colheita, 19 alunos haviam passado pelo bloco teórico e estágio de 
Enfermagem Pediátrica e Saúde Pública $e 23$ pelo de Enfermagem Obstétrica e Ginecológica e Saúde Pública, em enfermarias específicas e em ambulatórios e Unidades Básicas de Saúde da cidade;

- SEXTA COLHEITA - (em 11/12) realizada no final do curso, após os dois grupos de alunos terem completado o rodízio das atividades descrito na quinta colheita (inversão dos alunos).

\section{RESULTADOS E DISCUSSÃO}

As amostras obtidas da cavidade nasal (N) e mãos direita e esquerda (Md e Me) dos 42 alunos, em seis diferentes momentos, totalizaram 738 culturas. Convém ressaltar que as duas últimas colheitas não foram realizadas em seis alunos, por não terem comparecido no local no dia programado.

Do total de alunos, 5 (11,9\%) não apresentaram positividade ao Staphylococcus aureus em nenhuma das áreas anatômicas e colheitas realizadas, comportando-se como não portadores. Do total de culturas 197 (26,7\%) apresentaram resultado positivo para o Staphylococcus aureus, conforme Tabela 1 .

Tabela 1 - Freqüência de amostras positivas para o Staphylococcus aureus nos 42 alunos do curso de auxiliar de enfermagem, por colheita realizada

\begin{tabular}{ccccc}
\hline \multirow{2}{*}{ Colheitas } & $\mathrm{N}^{\mathrm{a}}$ & \multicolumn{3}{c}{ Número de Amostras } \\
\cline { 3 - 5 } & De & \multicolumn{3}{c}{ Positivas ao S. aureus } \\
\cline { 3 - 5 } & Examinados & Coletadas & $\mathrm{N}^{\mathbf{0}}$ & $\mathbf{\%}$ \\
\hline $1^{2}$ & 42 & 126 & 40 & 31,7 \\
$2^{2}$ & 42 & 126 & 24 & 19,0 \\
$3^{2}$ & 42 & 126 & 48 & 38,1 \\
$4^{2}$ & 42 & 126 & 46 & 36,5 \\
$5^{2}$ & 41 & 123 & 18 & 14,6 \\
$6^{a}$ & 37 & 111 & 21 & 18,9 \\
\hline TOTAL & $\mathbf{2 4 6}$ & $\mathbf{7 3 8}$ & $\mathbf{1 9 7}$ & $\mathbf{2 6 , 7}$ \\
\hline
\end{tabular}

Apesar da variação entre os resultados das diferentes colheitas (de $14,6 \%$ a $38,1 \%$ ), a taxa de colonização encontrada $(26,7 \%)$ enquadra-se nos limites de valores preconizados para a população adulta normal, que não tem ligação com o ambiente hospitalar (20 a 50\%) e não naqueles referidos para o pessoal que desempenha atividades hospitalares (30 a 70\%) ${ }^{7}$.

Observa-se uma freqüência maior de colonização na $3^{\mathrm{a}}(38,1 \%), 4^{\mathrm{a}}(36,5 \%)$ e $1^{\mathrm{a}}(31,7 \%)$ colheitas, quando os alunos haviam concluído o bloco teórico e estágio supervisionado junto às disciplinas de Enfermagem Médica e Cirúrgica e Disciplinas Instrumentais, respectivamente. Nas duas primeiras disciplinas, os alunos assumiam a assistência integral do paciente durante os estágios realizados nas unidades de internação, responsabilizando-se por todos os cuidados e procedimentos de enfermagem necessários para tal assistência, desde que já tivessem sido abordados em nível teórico.

As freqüências menores na segunda colheita $(19,0 \%)$, após o bloco teórico e estágio de Introdução à Enfermagem, $14,6 \%$ e $18,9 \%$ na quinta e sexta colheitas, após o bloco teórico e estágio supervisionado de Enfermagem Pediátrica e Saúde Pública e Enfermagem Ginecológica e Saúde Pública, respectivamente, levaramnos à reflexão da possível relação com o tipo de atividade desenvolvida pelos alunos e a característica do campo de estágio utilizado.

Quando da segunda colheita, conforme a programação do curso, os alunos haviam mantido o primeiro contato com o ambiente hospitalar, em diferentes unidades de internação médico-cirúrgica, porém com a preocupação apenas de executar as técnicas padronizadas e abordadas no bloco teórico sem, no entanto, assumirem a assistência do paciente; já na quinta e sexta colheitas, prestavam assistência à crianças e mulheres internadas em unidades hospitalares específicas e aos usuários de Centros de Saúde e Ambulatórios do Hospital. Provavelmente, o tipo de atividade desenvolvida junto aos pacientes, as características desses serviços e as condições de saúde dos pacientes podem ter influenciado nas taxas de colonização observadas.

Um fato importante que merece ser destacado é que, durante a fase de coleta de dados, conforme foi colocado na metodologia, 18 alunos $(42,9 \%)$ informaram já terem exercido atividades relacionadas à enfermagem, geralmente como atendentes, em instituições de saúde, antes de iniciarem o curso de Auxiliar de Enfermagem e que continuaram em exercício durante o desenvolvimento do mesmo. O período de atuação foi bastante variável, indo de apenas um mês à quinze anos. Esta consideração levou-nos à necessidade de conhecer a diferença de positividade nos dois grupos de alunos: os que não haviam desenvolvido atividades assistenciais de enfermagem antes elou durante o curso e os que haviam desenvolvido.

Os resultados obtidos não evidenciaram diferença na taxa de positividade entre os dois grupos, $26,6 \% \mathrm{e}$ $26,7 \%$, respectivamente, apesar das variações de freqüência entre as colheitas realizadas. Vale ressaltar que todos os alunos que afirmaram exercer atividades assistenciais antes do curso, continuaram exercendo-as durante o mesmo.

Dos alunos que referiram exercer atividades em instituições de saúde, 66,7\% desenvolviam-nas em 
Hospitais Gerais, que não os utilizados como campos de estágios no curso de Auxiliar de Enfermagem, sendo que apenas um aluno referiu trabalhar há dez anos e outro há quatro anos. O tempo de atividade dos demais variou de um a três meses, ainda que não tenha sido possível caracterizar as condições ambientais desses serviços, o tipo de paciente atendido e os tratamentos utilizados.

Os demais alunos $(33,3 \%)$ referiram exercer atividades em Hospital Psiquiátrico, Central de Esterilização, Creche e Unidade Básica de Saúde, cujas características de atendimento, aparentemente, diferem das desenvolvidas nos Hospitais Gerais, funcionando, quase sempre, como elo de ligação entre a organização hospitalar, o paciente e a comunidade.

Vale considerar também que, como já referimos em trabalho anterior ${ }^{13}$, apesar da categoria de atendente prestar cuidados direto aos pacientes, deve existir uma diferença na complexidade do cuidado executado entre este elemento e o auxiliar de enfermagem, em função do nível de preparo das duas categorias. Geralmente, as atribuições que exigem um grau mais elevado de perícia técnica são delegadas aos auxiliares de enfermagem e as mais simples, que dependem de conhecimentos elementares e que podem ser facilmente aprendidas, aos atendentes de enfermagem.

Ao buscar agora a relação da colonização pelo Staphylococcus aureus nas diferentes colheitas, por área anatômica examinada (Tabela 2), pode-se observar uma maior freqüência na cavidade nasal $(45,7 \%)$, seguida pela mão direita $(27,4 \%)$ e mão esquerda $(26,9 \%)$, confirmando o que a literatura tem revelado, ou seja, que as fossas nasais têm sido a área mais freqüentemente positiva para o Staphylococcus aureus ${ }^{13,23}$ e que, na maioria dos adultos, a colonização nasal é que "garante" a colonização da superfície cutânea.

Tabela 2 - Freqüência de amostras positivas para 0 Staphylococcus aureus entre os 42 alunos do curso de auxiliar de enfermagem, por área anatômica examinada e colheita realizada

\begin{tabular}{ccccc}
\hline \multirow{2}{*}{ Colheitas } & $\begin{array}{c}\text { N }^{\mathbf{2}} \text { de amostras } \\
\text { Positivas }\end{array}$ & \multicolumn{3}{c}{ Área Anatômica } \\
\cline { 3 - 5 } & $\begin{array}{c}\text { ao } \text { S. aureus } \\
1^{2}\end{array}$ & $\mathbf{N}$ & M d & Me \\
$2^{2}$ & 40 & 19 & 11 & 10 \\
3 & 24 & 12 & 6 & 6 \\
4 & 48 & 19 & 15 & 14 \\
$S$ & 46 & 21 & 13 & 12 \\
6 & 18 & 9 & 3 & 6 \\
\hline
\end{tabular}

Total

197
Esses fatos são relevantes para alertar sobre a importância das vias aéreas superiores na aquisição e transmissão de microrganismos, sobre a necessidade de educação continuada e controle bacteriológico periódico das pessoas que trabalham em ambiente hospitalar e aplicação de boas práticas de controle de infecção durante a prestação de assistência aos pacientes.

O aluno de Auxiliar de Enfermagem, a nosso ver, representa um exemplo que se enquadra dentro dessas considerações, uma vez que durante a sua formação se responsabiliza pela assistência ao paciente, em diferentes níveis de complexidade, sendo esta assistência marcada pelas características do trabalho manual, que requer um esforço e uma proximidade física entre ele e o receptor da mesma, aumentando as oportunidades favoráveis à disseminação de microrganismos e expondo ambos a determinados riscos de aquisição dos mesmos.

Em relação às mãos causou-nos surpresa as taxas encontradas, $27,4 \%$ e 26,9\%, nas mãos direita e esquerda, respectivamente. Em trabalhos realizados por nós ${ }^{12,13,14,15}$, as positividades encontradas foram menores do que a deste trabalho, ainda que a técnica de obtenção das amostras tenha sido a mesma e ainda que tenhamos identificado alguns elementos colonizados por amostras com modelos de antibiograma resistentes a até cinco antibióticos testados ou com fagótipos considerados de "identidade perigosa".

Sem querer entrar no mérito da técnica e da avaliação da maneira como o conteúdo foi ou tem sido abordado e exigido dos alunos durante o curso, percebese que o problema da lavagem das mãos continua o mesmo e que as mesmas permanecem representando uma importante fonte de propagação de bactérias, principalmente nas situações que requerem um contato direto entre prestador e receptor do cuidado.

Ao agruparmos agora a freqüência de colonização das amostras colhidas da cavidade nasal, mãos direita e esquerda, nos diferentes momentos de colheita, considerando ainda a atividade de trabalho desenvolvida pelos alunos, observamos uma pequena variação nas taxas de positividade nas diferentes áreas anatômicas, nos dois grupos de alunos. É importante considerar, no entanto, que fica difícil fazer uma análise segura desses resultados uma vez que, quando da obtenção das amostras, mesmo que em momentos diferentes, alguns alunos podem ter se comportado como portadores intermitentes ou ocasionais, não estando colonizados pelo Staphylococcus aureus no momento da colheita. Outros aspectos também mereceriam ser considerados, principalmente aqueles relacionados à necessidade de se conhecer a identidade das amostras isoladas e à dificuldade de se determinar, com segurança, as oportunidades de desenvolvimento de atividades de assistência dos alunos junto aos pacientes, durante o curso. 
Pela análise da distribuição dos alunos com positividade para o Staphylococcus aureus nas mãos direita (Md) e esquerda (Me), associada à cavidade nasal, por colheita realizada (Tabela 3), a exemplo de outros estudos $^{10,11,13}$, observamos que, de maneira geral, a proporção de colonização simultânea entre os alunos foi maior em quase todas as colheitas e que a maioria, 30 (88,2\%), apresentou positividade simultânea na cavidade nasal e em ambas as mãos. Estes dados vêm confirmar o considerado na literatura de que o portador nasal é quase sempre portador nas mãos e reforçar a possibilidade de propagação de microrganismos pelas mãos, principalmente quando se considera o cuidado direto prestado pelo aluno de Auxiliar de Enfermagem como possível meio de propagação de bactérias de um paciente infectado para outro suscetível, de um paciente infectado para o prestador dos cuidados, como também do prestador dos cuidados para um paciente suscetível.

Tabela 3 - Distribuição dos alunos do curso de auxiliar de enfermagem com positividade para o Staphylococcus aureus na mão direita e/ou esquerda, associada à cavidade nasal, por colheita realizada

\begin{tabular}{|c|c|c|c|c|c|c|c|c|c|c|c|c|}
\hline \multirow{4}{*}{ Colheitas } & \multicolumn{12}{|c|}{ Positividade para o Staphylococcus aureus } \\
\hline & \multicolumn{4}{|c|}{ Mão Direita } & \multicolumn{4}{|c|}{ Mão Esquerda } & \multicolumn{4}{|c|}{ Mão Direita + Mão Esquerda } \\
\hline & \multicolumn{2}{|c|}{$\mathrm{N}+$} & \multicolumn{2}{|c|}{$\mathrm{N}-$} & \multicolumn{2}{|c|}{$\mathrm{N}+$} & \multicolumn{2}{|c|}{$\mathrm{N}-$} & \multicolumn{2}{|c|}{$\mathrm{N}+$} & \multicolumn{2}{|c|}{$\mathrm{N}-$} \\
\hline & $\mathrm{N}^{\mathrm{a}}$ & $\%$ & $\mathrm{~N}^{\mathrm{a}}$ & $\%$ & $\mathrm{~N}^{\mathrm{a}}$ & $\%$ & $\mathrm{~N}^{\mathrm{a}}$ & $\%$ & $\mathrm{~N}^{\mathrm{a}}$ & $\%$ & $\mathrm{~N}^{\mathrm{a}}$ & $\%$ \\
\hline $1^{2}$ & 4 & 57,1 & 3 & 42,9 & 4 & 80,0 & 1 & 20,0 & 5 & 100,0 & - & - \\
\hline $2^{2}$ & 1 & 100,0 & - & - & 1 & 100,0 & - & - & 4 & 80,0 & 1 & 20,0 \\
\hline $3^{2}$ & 2 & 66,7 & 1 & 33,3 & 1 & 50,0 & 1 & 50,0 & 12 & 100,0 & - & - \\
\hline $4^{3}$ & 5 & 71,4 & 2 & 28,6 & 5 & 83,3 & 1 & 16,7 & 5 & 83,3 & 1 & 16,7 \\
\hline $5^{a}$ & - & - & 1 & 100,0 & 4 & 100,0 & - & - & 1 & 50,0 & 1 & 50,0 \\
\hline $6^{2}$ & 2 & 100,0 & - & - & 1 & 100,0 & - & - & 3 & 75,0 & 1 & 25,0 \\
\hline Total & 14 & 66,7 & 7 & 33,3 & 16 & 84,2 & 3 & 15,8 & 30 & 88,2 & 4 & 11,8 \\
\hline
\end{tabular}

\section{CONSIDERAÇÕES FINAIS}

A análise dos dados apresentados colocou em evidência os principais interagentes do estudo, destacando a participação do aluno portador de Staphylococcus aureus como possível fonte de infecção e o provável risco a que está exposto em função das atividades desenvolvidas durante o curso. Considerando a fundamentação utilizada, foi possível destacar que apesar da colonização ter oscilado durante o período estudado, não se pode deixar de considerar a possibilidade de transmissão recíproca deste agente entre os alunos e os receptores da assistência de enfermagem, considerando o tipo de contato mantido entre eles, bem como a necessidade de um ensino voltado para a importância da prevenção e do controle das infecções, através do conhecimento dos princípios científicos relativos às vias de penetração dos microrganismos, aos mecanismos de transmissão e aos fatores que predispõem o aparecimento de infecções.

\section{MONITORING THE COLONIZATION BY STAPHYLOCOCCUS AUREUS IN STUDENTS FROM A NURSING AUXILIARY PROGRAM DURING THE PROFESSIONAL FORMATION}

Considering our goal of understanding the colonization by Staphylococcus aureus in students from a nursing auxiliary program, during their professional formation, we collected material from the nasal cavity (N), right (Md) and left (Me) hands from 42 students on different moments of their formation relating the levels of colonization to the activities developed during the program. Results showed an oscillation in the colonization rate in different moments and the possibility of agent reciprocal transmission between the students and the taken care receptors, considering the type of contact. 
curso de auxiliar de enfermería durante su formación, realizamos la colecta de material de la cavidad nasal ( $N)$, manos derecha (Md) e izquierda (Me) de 42 alumnos, en diferentes momentos de su formación, relacionando las tasas con las actividades desarrolladas durante la programación del curso. Los resultados evidenciaron una oscilación en las tasas de colonización en los diferentes momentos y la posibilidad de transmisión mutua del agente entre los alumnos y los receptores de los cuidados, considerando el tipo de contacto mantenido entre ellos.

TÉRMINOS CLAVES: portador sano, Staphylococcus aureus, estudio longitudinal

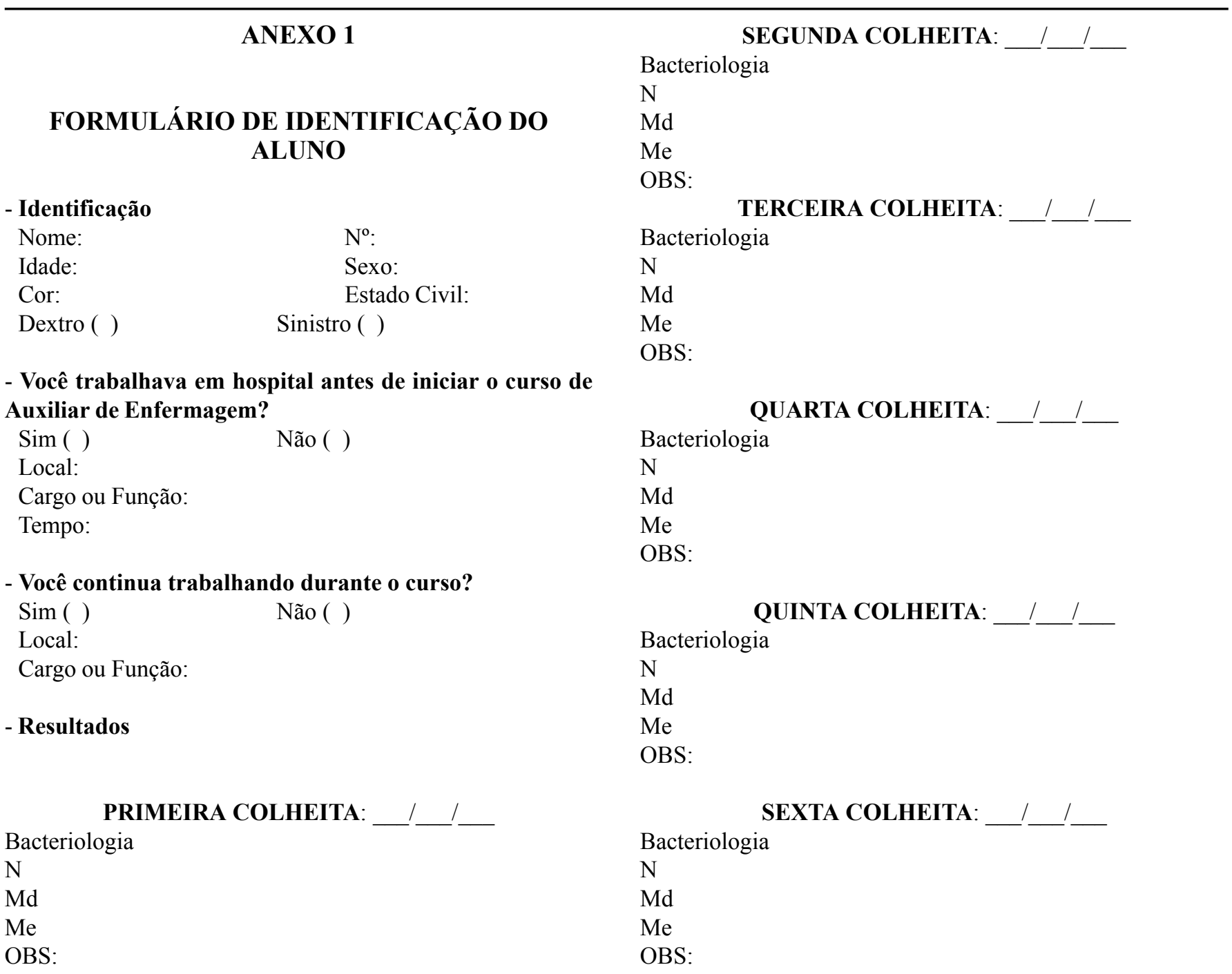

\section{REFERÊNCIAS BIBLIOGRÁFICAS}

01. ADAMS, B.C.; MARRIE, T.J. Hand carriage of aerobic gram-negative may not be transient. $\mathbf{J}$. Hygiene, v. 89, n. 1, p. 36-46, 1982.

02. BALDY, J.L.S.; LOPES, H.V. Estafilococcias. In: AMATO NETO, V.; BALDY, J.L.S. Doenças transmissíveis. São Paulo: Sarvier, 1991. cap. 33, p. 395-410.

03. BAYLISS, B.G.; HALL, E.R. Plasma coagulation by organism other than Staphylococcus aureus. J. Bacteriol., v. 89, n. 11, p. 101-105, 1965.

04. FERREIRA, M.S.; GONÇALVES, E.G.; ASSIS, V.P. Infecções estafilocócicas. Rev. Bras. Med., v. 42, n. 6 , p. 179-189, 1985.
05. GILBERT, P. Principles of microbiol pathogenicity and epidemiology. In: HUGO, W.B.; RUSSEL, A.D. Pharmaceutical microbiology. 5. ed. London: Blackwell Scientific, 1992. cap. 4, p. 82-96.

06. GOULD, D. Nurses' hands as vectors of hospitaladquired infection: a review. J. Adv. Nurs., v. 16, n. 10, p. 1216-1225, 1991.

07. MORTIMER, E.A. Possible mechanisms for vaginal infection whith Staphilococus aureus Ann. Intern. Med., v. 96, n. 2, p. 934-936, 1982.

08. NOBLE, W.C. Exogenous infection. In: NOBLE, W.C. Microbiol skin disease: its epidemiology. London: Edward Arnould, 1983. cap. 4, p. 4987. 
09. NOBLE, W.C. Microbiology of normal skin. In: NOBLE, W.C. Microbial skin disease: its epidemiology. London: Edward Arnould, 1983. cap. 2, p. 4-23.

10. NOBLE, W.C. Ward infection. Transactions of the St John's Hospital Dermatol. Soc., v. 54, p. 83, 1968.

11. NOBLE, W.C. et al. Carriage of staphylococcus aureus in randon samples of a normal population. J. Hygiene, v. 65, n. 4, p. 567-573, 1967.

12. OLIVEIRA SANTOS, B.M. de; UTHIDA TANAKA, AM. Prevalência de portadores sãos de Staphylococcus aureus em pessoal de diferentes categorias de enfermagem de um hospital geral escola. Medicina, v. 22, n. 1/2, p. 11-18, 1989.

13. OLIVEIRA SANTOS, B.M. de. Prevalência de portadores sãos de Staphylococcus aureus em pessoal de diferentes categorias de enfermagem de um hospital escola. Ribeirão Preto, 1987. 201p. Tese (Doutorado) - Escola de Enfermagem de Ribeirão Preto, Universidade de São Paulo.

14. OLIVEIRA SANTOS, B.M. de; AGUILLAR, O.M.; TAKAKURA, M.S. Colonização simultânea de Staphylococcus aureus na cavidade nasal e mãos de portadores sãos de um hospital escola. Rev. Microbiol., v. 21, n. 4, p. 309-314, 1990.

15. OLIVEIRA SANTOS, B.M. de; SCOCHI, C.G.S.; GARCIA E SOUZA, M.T. Prevalência de portadores sãos de Staphylococcus aureus em pessoal de enfermagem de unidades pediátricas de um hospital geral escola. Parte I. Rev. Paul. Hosp., v. 38, n. 1/2/3/4, p. 24-29, 1990.
16. OLIVEIRA SANTOS, B.M. de; SCOCHI, C.G.S.; GARCIA E SOUZA, M.T. Marcadores epidemiológicos de amostras de staphylococcus aureus em pessoal de enfermagem de unidades pediátricas de um hospital geral escola-Parte II. Rev.Paul. Hosp., v. 38, bn.5/6/7/8, p. 53-57, 1990.

17. POLAKOFF, S. et al. Nasal and skin carriage of staphylococcus aureus by patients undergoing surgicall operations. J. Hygiene, v. 65, n. 4, p. 559-566, 1967.

18. ROUQUARYROL, M.Z.; VERAS, F.M.F. Doenças transmissíveis e modos de transmissão. In: ROUQUARYROL, M.Z. Epidemiologia e saúde. 4. ed. Rio de Janeiro: MEDSI- Editora Médica e científica, 1994. p. 217-268.

19. SOLÉ-VERNIN, C.; UTHIDA TANAKA, A.M. Staphylococcus aureus e as estafilococcias humanas. In: VERONESI, R. Doenças infecciosas e parasitárias. Rio de Janeiro: Guanabara Koogan, 1983. p. 264-275.

20. SOMERVILLE, D.A. The normal flora of the skin in different age groups. Br.J. Dermatol., v. 81, n. 4, p. 248-258, 1969.

21. SOUNIS, E. Epidemiologia geral. Rio de Janeiro: Atheneu, 1985. p. 1-96.

22. TOLEDO, M.R.F. Staphylococcus. In: TRABULSI, L.R. Microbiologia. 2. ed. Rio de Janeiro: Atheneu, 1989. cap. 17, p. 105-109.

23. WILLIAMS, R.E.O. Healthy carriage of Staphylococcus aureus: its prevalence and importance. Bacteriol. Rev., v. 27, n. 1, p. 5671, 1963. 